\title{
Development of Phonetic Categories of Stop Consonants in Spanish-English Bilingual Children
}

Andrea M. Muru and Sue Ann S. Lee

Department of Speech-Language-Hearing Sciences, Texas Tech University Health Sciences Center, Lubbock, TX, USA

Purpose: The present study examined stops produced by Spanish-English bilingual (SEB) children in order to determine whether the bilingual children possess distinct phonetic categories across their two languages at 5 to 6 and 10 years of age.

Methods: Voice-Onset-Time (VOT) of English and Spanish stops were measured acoustically. VOT values of each place of articulation were compared across languages in each age group separately.

Results: It was found that 5- to 6-year-old SEB children only made significant distinctions between English and Spanish for voiceless stop consonants; however, 10-year-old SEB children demonstrated distinctive categories between the two languages for both voiced and voiceless stops.

Conclusions: The findings suggest that similar to previous studies, distinctive phonetic category is only partially developed at age 5 to 6 but it is developed fully by age 10 . While developing, a transfer effect existed in the SEB children's stop production.

Keywords: Stop consonents, Spanish-English bilingnals, Children, Voice-Onset-Time

\section{INTRODUCTION}

The U.S. Census Bureau [1] indicated that Spanish ranks as the \#1 non-English language spoken in the United States. Over 37 million Spanish speakers including 6 million Spanish-speaking children reside in the United States, a number that has more than doubled over the last 30 years. In spite of the significant number of Spanish-English bilingual children, literature on the developmental norms of these children is limited and has revealed a paucity of information on developmental patterns. Investigating the typical development of Spanish-English bilingual children is necessary in order to establish typical developmental patterns and milestones.

Differences in onset of second language (L2) exposure divide bilingual speakers into simultaneous and sequential speakers. Researchers [2-4] proposed arbitrary age cutoffs point for categorizing these two categories. Generally speaking, simultaneous bilingual speakers are those who have been exposed to the L2 within the first few years of life and continue to acquire the L2 along with L1. Sequential bilingual speakers differ from simultaneous bilinguals in that significant progress or almost complete acquisition of the L1 has been made before exposure to the L2.

The purpose of this study was to provide the development characteristics of phonetic
(

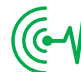

(1) 
categories of stop consonants in sequential Spanish-English bilingual children. Development of phonetic category refers to the phonetic refinement process by which bilingual children come to distinguish phonetic details of shared phonemes in each language during development [5]. Spanish and English present an interesting opportunity for evaluating age of acquisition of phonetic systems in bilingual children because voiced and voiceless stop consonants at three places of articulation such as /p/, /b/, /t/, /d/, /k/ and /g/ are found in both languages but voiced and voiceless stop at each place are produced with different voice-onset-time values. Thus, investigation of the voicing contrast of stop consonants between the two languages allows us to evaluate whether SpanishEnglish bilingual speakers establish distinct phonetic categories between languages.

Research into language acquisition in bilingual children has generally focused on whether these children develop one or two linguistic systems. The one-system model, known as the Unitary Language System (ULS), was originally hypothesized by Volterra and Taeschner [6] and the two-system model, also known as the Dual Language Hypothesis, was posited by Genesee [7]. Under a one-system model, during early language development, bilingual children would take received input from both languages and combine the information into a single language system. As the language acquisition process continues, bilingual children develop more advanced linguistic skills, and undergo a differentiation process. It is during this process that these children distinguish between languages and achieve bilingual status. The Dual Language System (DLS) hypothesis stands as an alternative to the ULS hypothesis. The DLS hypothesis posits that children establish two separate linguistic systems from the beginning of the language acquisition process. Under this model, children receive dual language input and separate this information into two distinct language systems. These children may not undergo a period in which their linguistic systems are merged.

\section{Stop consonants of English and Spanish}

Before discussing previous bilingual studies, it is important to review the stop consonants of Spanish and English. Both English and Spanish stops are composed of voiced and voiceless at three places of articulation: labial, coronal and velar. English and Spanish stops, however, differ in their acoustic characteristics. Voice-Onset-Time (VOT) is commonly used to characterize stops across languages. Lisker and Abramson [8] defined VOT as "the duration of the time interval by which the onset of periodic pulsing either precedes or follows release" (p. 387). Lisker and Abramson established three cross-linguistic voicing contrasts: lead voicing, short lag and long lag. Lead voicing (or voicing lead) refers to instances in which voicing begins before the release of the stop. Short lag refers to voicing that begins just after the release of the stop. Long lag refers to voice onset lags that begin after the stop release and are considerably longer than short lag. By assigning a zero value to the point at which the stop is released, lead voicing is assigned a negative value while voicing after the stop release are assigned positive values.

Acoustic analysis of stop productions indicates that the phonetic basis for the voiced and voiceless distinction is not the same in English and Spanish. Spanish voiced stop consonants are characterized by the onset of voicing prior to the release of the stop (mean VOT =-113 milliseconds), whereas the onset of voicing for English voiced stop consonants begins shortly after the release of the stop burst (mean VOT $=9$ milliseconds). Voicing for Spanish voiceless stops, like English voiced stops, begins shortly after the release of the stop burst (mean VOT = 14 milliseconds) while voicing in English voiceless stops begins an average of $60-80$ milliseconds (mean VOT $=70$ milliseconds) after release of the stop burst [8].

\section{Phonetic development of stop consonants in monolingual children}

Macken and Barton [9] investigated the acquisition of the voicing contrast in four monolingual English-speaking children aged $1 ; 6$ for eight months. They found that the presence of the English voicing contrast was found in three of the four participants by approximately age 1; 9 and by at least age 2; 6 in the fourth participant. Macken and Barton [10] also investigated the acquisition of the voicing contrast in three monolingual Spanish-speaking children aged 1; 7 and four monolingual Spanish speaking children aged 3; 10. Although the monolingual Spanish speaking children differentiated between voiced and voiceless stops, they primarily did so using spirantization rather than a VOT distinction. At age $3 ; 10$, study participants were unable to consistently differentiate voiced and voiceless stop consonants using lead voicing and short lag VOT categories.

\section{Phonetic category development in bilingual children}

Research done on the development of phonetic category formation in bilingual children has provided some interesting evidence in support of theories claiming that bilingual chil- 
dren have two separate phonetic systems that interact with each other. Within this body of research, particularly VOT development is of particular interest to this study. As Kehoe, Lleo and Rakow [11] note, VOT is particularly susceptible to interaction between two languages in bilingual speakers.

Deuchar and Clark [12] utilized the voicing feature distinction between English and Spanish to examine the acquisition and interaction of phonetic systems in a simultaneous bilingual child at $1 ; 7,1 ; 11$, and 2; 3 ages. The data reflected the lack of a voicing system in both English and Spanish at age 1; 11, the establishment of a clear voicing system in English at age 2; 3 but only the beginnings of a similar system in Spanish. The Spanish data did not reflect a Spanish-adult speaker voicing contrast but rather progression towards an English-adult speaker voicing contrast. In terms of across English and Spanish languages, voiceless stops were significantly different from each other whereas voiced stops were not until this age. The authors argued that there was not a single and unified English and Spanish system in the child and the greater differences of the lag between English stops pairs lead to the earlier acquisition of the pairs.

Kehoe, Lleo and Rakow [11] examined VOT in four German-Spanish bilingual children aged 2; 0 to 3; 0 . Like English and Spanish, German and Spanish are similar in that they both have the voiced (/b, d, g/) and voiceless stop consonants $(/ \mathrm{p}, \mathrm{t}, \mathrm{k} /)$ but differ in their expression of voicing contrasts. German stops like English are produced with short and long lag whereas Spanish stops are produced with lead voicing and short lag. The authors found that two children failed to acquire the German voicing distinction, thus producing voiceless stops using short lag. However, the other two bilingual children were able to acquire the German voicing distinction by age $2 ; 3-2 ; 6$. On the other hand, results from the data collected in Spanish were more uniform in that none of the bilingual children consistently produced voiced stops with lead voicing. In terms of across languages, only two children made a distinction between German and Spanish voiceless stops.

The results of Kehoe et al's [11] study seem to be consistent with the study conducted by Deuchar and Clark [12]. Voicing systems with an opposition between short and long lag, such as those found within English and German, appear to be acquired earlier than voicing systems with an opposition between lead voicing and short lag, as is found within Spanish.

Recently, Fabiano-Smith and Bunta's [13] study investigated the VOT of voiceless bilabial and velar stop consonants in Spanish and English by comparing the productions of Span-
ish-English bilingual children to that of Spanish and English monolinguals. Results indicated that VOT values produced by Spanish-English bilingual children differed from their monolingual counterparts in English but not in Spanish, suggesting cross-language influence within the bilingual children. Although there was a statistically significant difference between the VOT values produced by English and Spanish monolinguals, no significant differences were found between the VOT values for the Spanish and English stops produced by Spanish-English bilingual children, which indicated no languagebased differentiations. The findings of the study contradicted previous studies in that they reported that voicing distinction between English and Spanish voiceless stops were emergent at an early age, but this study did not find the same results. Previous studies examined simultaneous bilingual children, while this study included both simultaneous and sequential bilingual children. Thus, the homogeneity of participants may affect the findings.

In terms of older bilingual children, Khattab [14] compared the VOT values produced by three Arabic-English bilingual children to those of three monolingual English and three monolingual Arabic children aged at 5, 7, and 10. Arabic VOT patterns are similar to those of Spanish in that the voiced stops $/ \mathrm{b}, \mathrm{d}, \mathrm{g} /$ fall within the lead voicing range and the voiceless stops $/ \mathrm{p}, \mathrm{t}, \mathrm{k} /$ fall within the short lag range. Results indicated that the three English-Arabic bilingual children did acquire separate VOT patterns for English and Arabic; however, the VOT patterns were not always consistent with those of monolingual speakers. The lead voicing pattern in Arabic seemed to be primarily affected as voiced Arabic stops tended to fall within the short lag range. Khattab found an interesting developmental pattern. The 5-year-old English-Arabic bilingual child produced voiced Arabic stops (/b, d, g/) with short lag rather than using the adult VOT pattern (i.e., lead voicing). While the 10-year-old child still had not acquired the lead voicing feature, the 7-year-old child primarily used lead voicing when producing voiced stops in Arabic. Since only one child was included in each age group, such a pattern may not reflect stop production in English-Arabic bilingual children. Thus, further studies with a larger number of bilingual children at various ages are warranted in order to identify more precise developmental patterns of stop production in bilingual children.

In fact, Lee and Iverson [15] conducted a larger scale study examining phonetic categories of Korean and English stops in Korean-English bilingual children. This study included 30 Ko- 
rean-English bilingual (KEB), 30 Korean monolingual, and 30 English monolingual children at two different ages (5 and 10 years of age). Examining Korean and English stops was of interest in that, unlike English, Korean stops show a three-way contrast. The three-way contrast for Korean stop productions is categorized into "lenis", "aspirated", and "fortis". Lee and Iverson note that in addition to VOT, other cues such as the vowel onset $f 0$, are available to Korean speakers when making distinctions between Korean stops. The complexity of the Korean system may present additional difficulties for bilingual children acquiring phonetic categories. Lee and Iverson found that 5-year-old KEB children only made distinctions between different categories (i.e., voiced-lenis, voiced-aspirated and voiceless-fortis). However, 10-year-old KEB children showed within category distinctions which indicated that they had developed fully separate phonetic categories across languages.

\section{Purpose}

The purpose of this study was to investigate the development pattern of phonetic stop category in Spanish-English bilingual children. The methodology of the current study differed from the previous studies in several ways. First, the current study examined older aged Spanish-English bilingual children at two different age ranges (5 to 6 and 10 years of age). Previous studies examining phonetic category in Spanish-English bilingual children were conducted with young children (e.g., younger than 4-year-olds). The results of the current study will provide a developmental model of bilingual children's speech. Second, unlike the previous studies, which employed a small number of bilingual children, the current study employed a larger number of bilingual children. Each age group included 15 or 17 bilingual children and more to consolidate findings. The results of the current study will provide more convincing evidence on phonetic category formation in bilingual children. Third, while the previous studies mainly compared bilingual children with their monolingual counterparts, the current evaluation focused on comparing the English and Spanish stop system among bilingual children. Such evaluation would allow us to understand whether the Spanish-English bilingual children possess one or two separate phonetic systems between languages. Finally, homogeneity of bilingual children in the previous studies was not well established. Both simultaneous and sequential bilingual children were included. Evaluating a more homogenous group may consolidate group characteristics of bilingual children.

\section{METHODS}

\section{Participants}

A total of 32 Spanish-English bilingual children participated in this study. Fifteen children were 10 years of age $(M=10 ; 6)$ and the other 17 Kindergarten children were 5 to 6 years of age $(M=5 ; 10)$. None of the participating children had a history of speech and hearing impairment based on reports from parents or teachers. The bilingual children were either born in the United States or had moved to the U.S. at an early age. All of the children were sequential bilingual children in that they had first learned Spanish and began learning English upon entering English preschool or kindergarten settings. The 10-year-old children had been exposed to both English and Spanish for 5-7 years $(\mathrm{M}=6 ; 3)$ whereas the 5 - to 6-year-old children had 2-3 years of exposure $(M=2 ; 5)$. At the time of this study, they communicated primarily in English with siblings and peers at school and Spanish with parents and grandparents at home.

\section{Stimuli}

Six English and six Spanish words were selected to elicit target stop consonants in the word initial position. In order to control variations, target words were selected in which the stop consonants occur in a similar vocalic environment (i.e., low vowels) for both languages. See Table 1 for a list of the target words in English and Spanish.

\section{Recordings}

Bilingual data were collected at schools and kindergartens in a quiet room. Target words were recorded using a digital flash recorder (Marantz Model PMD670) which was connected to a stand-mounted omni-directional dynamic microphone (Electro-Voice $635 \mathrm{~A} / \mathrm{B}$ ) positioned on a table. The participants' speech was recorded at a sampling rate of $22 \mathrm{kHz}$. While being recorded, subjects sat at a table with a microphone positioned approximately 4 to 6 inches away from them.

Table 1. Target words used to elicit stop consonants in English and Spanish

\begin{tabular}{lccccc}
\hline & \multicolumn{2}{c}{ English } & & \multicolumn{2}{c}{ Spanish } \\
\cline { 2 - 3 } \cline { 5 - 6 } & Voiced & Voiceless & & Voiced & Voiceless \\
\hline Bilabial & Bark & Park & & Banco "bank" & Papel "paper" \\
Alveolar & Dark & Tarzan & & Dar "gift" & Taza "cup" \\
Velar & Garden & Car & & Gato "cat" & Cabra "goat" \\
\hline
\end{tabular}




\section{Data collection and selection procedure}

Spanish and English target words were elicited using picture naming tasks. English and Spanish data were collected from a fluent English-Spanish bilingual investigator. During English elicitations, all conversations were conducted in English only, and during Spanish elicitations all conversations were conducted in Spanish. The order of elicitation of the English or Spanish language was randomized. Picture cards were randomly presented to each child. Then, the participant was asked to repeat the word three times with 2 second pause between productions. Although most children were familiar with the target words, when words were unknown the researcher utilized the delayed imitation technique by embedding the target word in a sentence and then asking the child to name the object or person in the picture. The delayed imitation technique is a common strategy used to elicit target words that are unknown to a child when administering phonology and articulation tests and conducting research [16-18]. For example, the investigator produced the target word (e.g., Tarzan) in a sentence and then asked the child for the target word: "This is Tarzan. He is a famous movie character. Who is this?"

\section{Data analysis}

Recordings collected from the participants were analyzed utilizing Multi Speech Software by Kay Elemetrics. Using both waveforms and wide-band spectrograms, VOT values for each target stop consonant were measured (a) from the beginning of the stop release and (b) to the onset of voicing in the vowel.
VOT values of three tokens of each stop were averaged in each children.

\section{Statistical analysis}

The current study adopted nonparametric statistics, that is, the Wilcoxon signed-rank test because data showed substantial variability in stop productions by SEB children. Using the Wilcoxon signed-rank test, the following English and Spanish stop pairs were compared at three places of articulation separately: English voiced vs. Spanish voiced, English voiced vs. Spanish voiceless, English voiceless vs. Spanish voiced and English voiceless vs. Spanish voiceless. In order to counteract the problem of multiple comparisons and reduce the occurrence of type 1 error the Bonferroni correction was used. The alpha level was adjusted by dividing the level of significance (i.e., .05) by the number of comparisons in order to arrive at an adjusted alpha level of $0.0125(.05 / 4)$.

\section{RESULTS}

The first research question investigated whether or not SEB children established distinct phonetic categories between languages. The second research question investigated whether or not distinct phonetic categories are established at 5 to 6 years old and at 10 years old. Tables 2 and 3 show means and standard deviations (SD) of VOT values for English and Spanish voiced and voiceless stops at three places of articulation; bilabial, alveolar and velar at age 5 to 6 years and 10 years, respectively. Within subject comparisons were made

Table 2. Means and Standard Deviations for English and Spanish VOT at 5 to 6 years of age

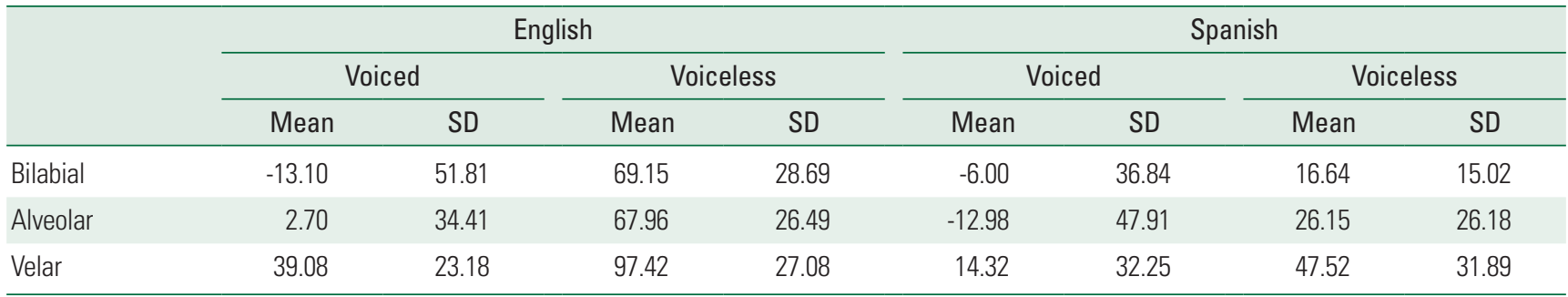

Table 3. Means and Standard Deviations for English and Spanish VOT at 10 years of age

\begin{tabular}{|c|c|c|c|c|c|c|c|c|}
\hline & \multicolumn{4}{|c|}{ English } & \multicolumn{4}{|c|}{ Spanish } \\
\hline & \multicolumn{2}{|c|}{ Voiced } & \multicolumn{2}{|c|}{ Voiceless } & \multicolumn{2}{|c|}{ Voiced } & \multicolumn{2}{|c|}{ Voiceless } \\
\hline & Mean & SD & Mean & SD & Mean & SD & Mean & SD \\
\hline Bilabial & 18.43 & 31.28 & 80.94 & 28.44 & -10.05 & 33.84 & 16.09 & 9.17 \\
\hline Alveolar & 20.32 & 37.23 & 79.79 & 27.76 & -19.29 & 35.44 & 18.83 & 6.80 \\
\hline Velar & 23.63 & 49.04 & 110.73 & 24.80 & -4.55 & 34.25 & 24.42 & 20.64 \\
\hline
\end{tabular}


using the Wilcoxon signed-rank test to determine the differences in VOT at each places of articulation between Spanish and English productions at 5 to 6 years of age and 10 years of age.

\section{VOT values for 5- to 6-year-old bilingual children in English and Spanish}

Figure 1A shows the mean and standard deviation of the VOT values for English and Spanish stops at the bilabial place of articulation. The 5- to 6-year-old SEB children produced both English and Spanish /b/ with negative VOT values. Differences were seen between languages in the production of $/ \mathrm{p} /$. English /p/ was produced with a long-lag VOT whereas Spanish /p/ was produced with a short-lag VOT. Voiced stops were produced with greater variability than voiceless stops.

The means and standard deviations for English and Spanish stops at the alveolar place of articulation are shown in Figure 1B. The VOT value for English /d/ was positive but remained close to zero whereas Spanish /d/ was a negative value. Similar to bilabial place, English /t/ was produced with a long-lag and Spanish / $\mathrm{t} /$ was produced with a short-lag.

Figure 1C also shows the mean and standard deviation of the VOT values for velar place of articulation. Unlike the bilabial and alveolar places, SEB children produced all stops with positive VOT values. English /g/ and Spanish /g/ and /k/ were produced with a short-lag VOT whereas English / k/ was pro- duced with a long-lag VOT. Upon comparison, SEB children produced Spanish /g/ with the smallest VOT value.

Results from the Wilcoxon signed-ranks test indicated that English /b/ and Spanish /b/ were not significantly different $(z=.21, p=.831)$. Also, English $/ \mathrm{b} /$ and Spanish $/ \mathrm{p} /$ were also not significantly different either $(z=-1.77, p=.076)$. However, Spanish /b/ was significantly different from English /p/ $(z=$ -3.57, $p=.000$ ) and English /p/ and Spanish /p/ were significantly different $(z=-3.47, p=.001)$. In terms of the alveolar place of articulation, results indicated that English /d/ and Spanish /d/ pairs and English /d/ and Spanish /t/ pairs were not significantly different $(z=-.54, p=.586$ for English $/ \mathrm{d} / \mathrm{vs}$. Spanish /d/; $z=-1.82, p=.068$ for English /d/ vs. Spanish /t/). However, English / $\mathrm{t} /$ and Spanish /d/ were significantly different $(z=-3.62, p=.000)$ as were English $/ \mathrm{t} /$ and Spanish $/ \mathrm{t} /(z=$ $-3.24, p=.001)$. Results from the velar place of articulation indicated that English /g/ and Spanish /g/ were not significantly different $(z=-2.15, p=.031)$; nor were Spanish $/ \mathrm{k} /$ and English $/ \mathrm{g} /(z=-.26, p=.795)$. English $/ \mathrm{k} /$ and Spanish $/ \mathrm{g} /$ were significantly different $(z=-3.62, p=.000)$ as were Spanish $/ \mathrm{k} /$ and English $/ \mathrm{k} /(z=-3.43, p=.001)$.

\section{VOT values for 10-year-old bilingual children in English and Spanish}

Figure $2 \mathrm{~A}$ shows the mean and standard deviations of the VOT values for English and Spanish stops at the bilabial place
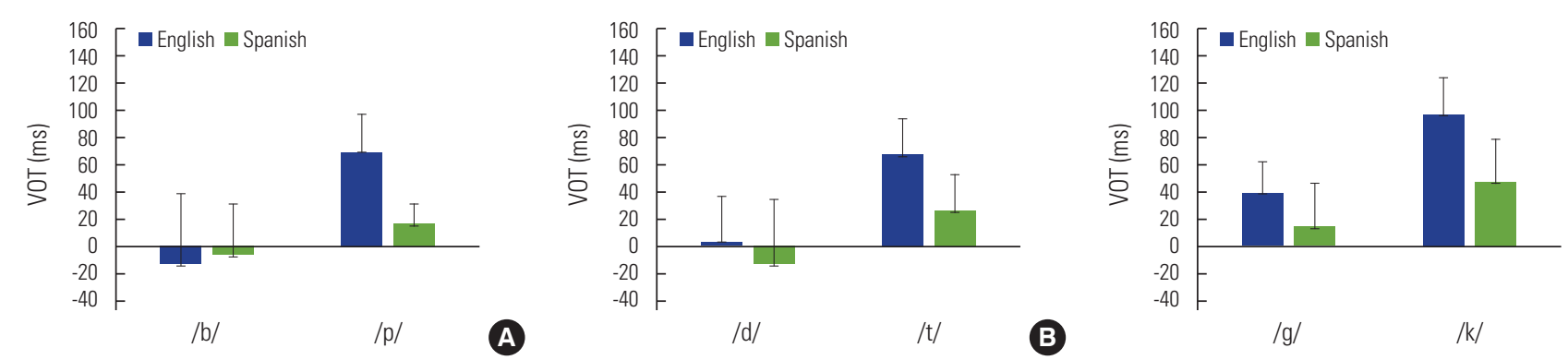

Figure 1. Means and standard deviations of English and Spanish VOT Values produced by 5- to 6-year-old SEB children.
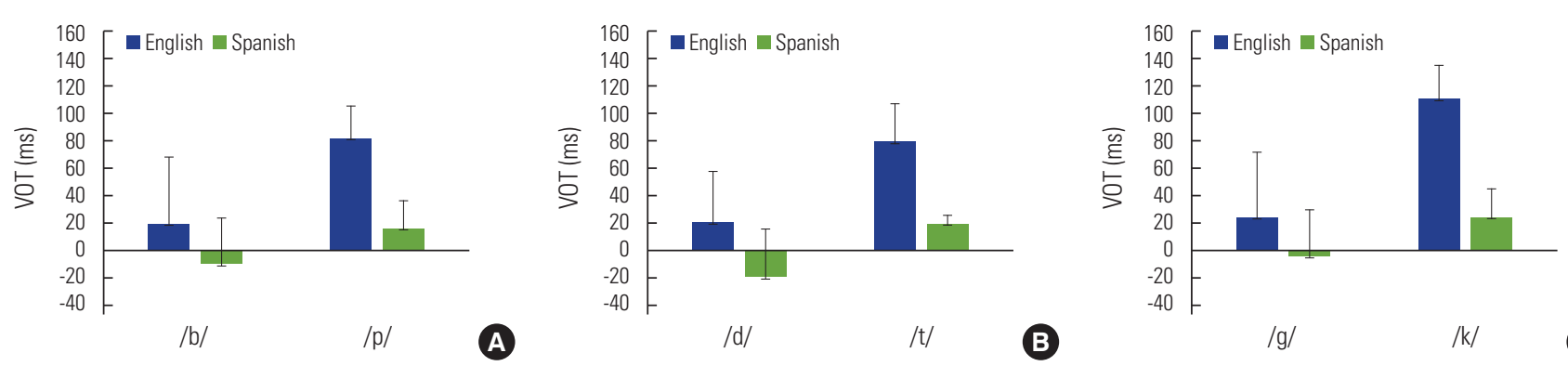

Figure 2. Means and standard deviations of English and Spanish VOT Values produced by 10-year-old SEB children. 
of articulation. Ten-year-old SEB children produced English /b/ with a positive VOT value but Spanish /b/ with a negative VOT value. English and Spanish /p/ were both produced with positive VOT values. Differences were seen between languages in the production of $/ \mathrm{b} /$ and $/ \mathrm{p} /$. English $/ \mathrm{b} /$ was produced with short lag VOT whereas Spanish /b/ was produced with lead voicing VOT. English /p/ was produced with long lag VOT and Spanish /p/ was produced with short lag VOT. Greater variability was seen with bilabial voiceless stops than voiceless stops. The mean and standard deviation for English and Spanish stops at the alveolar place of articulation is shown in Figure 2B. VOT values were also similar to those at the bilabial place of articulation. English /d/ and Spanish /t/ were both produced with short lag VOT. Spanish /d/ was produced with lead voicing VOT and English / $t$ / with long lag. Greater variance was seen between alveolar voiced and voiceless stops than bilabial voiced and voiceless stops. Comparisons at the alveolar place of articulation indicated greater variance between voiceless stops than voiced stops. Figure $2 \mathrm{C}$ shows the mean and standard deviation of the VOT values for the velar place of articulation. VOT values were similar to the bilabial and alveolar places, SEB children produced English /g/, English /k/ and Spanish /g/ with positive VOT. The VOT value for Spanish $/ \mathrm{g} /$ was a negative value, but was close to zero. English /g/ and Spanish /k/ were produced with short lag VOT, while English / k/ was produced with long lag. Results also indicated greater variability between voiceless and voiced velar stops. SEB children produced Spanish /g/ with the smallest VOT value.

The Wilcoxon signed-ranks test for SEB children at 10 years indicated that English / $\mathrm{b} /$ and Spanish /b/ were significantly different $(z=-2.61, p=.009)$, as were English $/ \mathrm{p} /$ and Spanish $/ \mathrm{b} /(z=-3.40, p=.001)$, and English $/ \mathrm{p} /$ and Spanish $/ \mathrm{p} /(z=$ $-3.40, p=.001)$. Spanish $/ p /$ was not significantly different from English $/ \mathrm{b} /(z=.05, p=.955)$. Comparisons made at the alveolar place of articulation indicated that English /d/ and Spanish /d/ differed significantly $(z=-2.95, p=.003)$, as did English /t/ and Spanish /d/ $(z=-3.40, p=.001)$, and English / t/ and Spanish /t/ $(z=-3.40, p=.001)$. However, English /d/ and Spanish / $\mathrm{t} /$ were not significantly different $(z=-1.53$, $p=.125)$. Finally, results from the velar place of articulation indicated that English / $/ \mathrm{k}$ and Spanish /g/ were significantly different $(z=-3.40, p=.011)$ as were English $/ \mathrm{k} /$ and Spanish $/ \mathrm{k} /(z=-3.40, p=.011)$. English /g/ did not differ significantly from Spanish /g/ $(z=-1.98, p=.047)$ when Bonferroni correction was applied. There no significant difference between
English /g/ and Spanish /k/ $(z=-1.25, p=.211)$ either.

To summarize our results, paired comparisons between VOT values of stop productions in 5- to 6-year-old SEB children showed significant differences for Spanish and English voiceless stops only, but not for voiced stops at three places of articulation. Results of paired comparisons between VOT values of stop productions in 10-year-old SEB children showed significant differences not only for Spanish and English voiceless stops but also for voiced stops at the bilabial and alveolar place of articulation. One exception was that no significant difference was found between English voiced and Spanish voiced for velar place of articulation.

\section{DISCUSSION}

The main findings of the current study showed that 5- to 6-year-old SEB children only made significant distinctions between English and Spanish for voiceless stop consonants; however, 10-year-old SEB children demonstrated distinctive categories between the two languages for both voiced and voiceless stops. Evaluation of these findings were used to: 1) determine whether or not SEB children establish distinct phonetic categories between languages and 2) if SEB children do establish distinct phonetic categories between languages, whether these distinctions are present at 5- to 6 years old and at 10 years old.

In the current study, significant differences between English and Spanish voiced and voiceless stops in 10-year-old bilinguals showed that separate phonetic categories were established between languages. The results of the current study were consistent with Khattab [14] and Lee and Iverson [15]. Khattab showed that fully distinctive phonetic categories were established at 7 years old in Arabic-English bilingual children. Lee and Iverson also reported distinctive phonetic category formation at 10 years old in Korean-English bilingual children. These results indicated that bilingual children at 7 years of age or older were able to distinguish phonetic categories across their two language systems regardless of language backgrounds.

Unlike the 10-year-old SEB children, 5- to 6-year-old bilinguals only demonstrated distinction between English and Spanish voiceless stops. These results indicated only partial phonetic category distinction between languages. Five-yearold Arabic-English bilingual children in Khattab [14] also showed only partial phonetic category formation. However, these findings were different from Lee and Iverson [15] in that 
KEB children did not manifest phonetic category formation in Korean bilingual children at age 5 . The different results may be attributed to the fact that Korean stops are more complicated than English and Spanish. Korean stops include the three-way distinction, lenis, fortis, and aspirated while English stops have a two-way distinction, voiced and voiceless. Data from these studies indicated that bilingual children at 5 years of age were only able to make partial phonetic category distinctions between languages.

One may ask why the SEB children did not show any distinction between English voiced and Spanish voiceless stops. Based on Lisker and Abramson's [8] classification, both Spanish voiceless and English voiced stops typically fall into the same VOT category (i.e., short-lag VOT) and are found to be non-significant when they are compared in terms of VOT. Thus, we may not expect to find significant difference between these two stops.

The current study provided useful information to further our understanding of the developmental patterns of phonetic categories across languages. Recall that Fabiano-Smith and Bunta [13] found no significant differences between English and Spanish VOT values at 3 years of age. A qualitative analysis of mean VOT values also shows similarities between Spanish and English, particularly for bilabial voiceless stops. These results suggested that at 3 years of age SEB children may not establish distinctive phonetic categories.

Unlike bilingual children at 3 years of age, the 5- to 6-yearold children in the current study showed an emerging pattern for phonetic categories. Distinctive phonetic categories for voiceless Spanish and English stops appeared in SEB children at 5 to 6 years of age. On the other hand, SEB children at 10 years of age demonstrated fully distinctive phonetic categories. While 5- to 6-year-old SEB children showed distinctions between voiceless stops but failed to do so for voiced stops, 10-year-old SEB children showed distinction between languages for both voiceless and voiced stops. Thus, these findings indicate that acquisition of phonetic categories in bilingual children is a gradual process.

It should be noted that while Fabiano-Smith and Bunta [13] did not find VOT differences between English voiceless and Spanish voiceless stops in their 3-year-old Spanish-English bilingual children, Deuchar and Clark [12] and Kehoe et al. [11] found that a few bilingual children were able to distinguish voiceless stops across languages at an early age. Thus, it may be premature to claim that 2-3-year-old Spanish-English bilingual children possess one or two phonetic systems in their respective languages based on the currently available data. Further studies are warranted to examine with young SEB children.

The 5- to 6-year-old SEB children in the current study appeared to be producing the English voiced bilabial stop with Spanish-like VOT patterns (i.e., lead voicing). This pattern may be explained by a transfer effect described by Paradis and Genesee [19]. They hypothesized that sounds or sound patterns found in one language will transfer to the other language system. For example, English voiced stops, which are typically produced with short lag VOT, may be produced with voicing lead because of influence from Spanish voiced stops. FabianoSmith and Goldstein [17] investigated between-language interactions affecting phonological acquisition in SEB children. They found that $25 \%$ of bilingual children demonstrated instances of transference between Spanish and English. This was seen in the production of English aspirated stops (voiceless stops) without aspiration, a characteristic commonly seen in Spanish [8].

Flege [20] cited data from Port and Mitleb [21] as support for postulating that the process of category formation in the L1 sound system can be applied to the L2. Flege [22] incorporated this idea into the first of his four postulates. Port and Mitleb [21] found that the phonetic characteristics of bilingual children's L1 influenced stop productions in English such that they were produced with Arabic characteristics. Evidence from VOT productions by 5 -year-old SEB children supported Flege [22]. In the current study, 5-year-old SEB children produced English bilabial voiced stops with Spanish phonetic characteristics (i.e., lead voicing VOT).

Recall that previous studies $[11,12]$ reported that Spanish voiced stops produced by SEB children fell in the short lag VOT category, which suggested that SEB children might need more time to fully realize adult-like Spanish voiced stops. For example, Deuchar and Clark [12] found that at 2; 3 the SEB child had established the English voicing system but their Spanish voicing system was comparable to that of English. Kehoe et al. [11] looked at German and Spanish VOT patterns in bilingual children between 2; 0 and 3; 0 . Bilingual productions within this study were similar to that of Deuchar and Clark [12] in that the bilingual children also appeared to be producing Spanish stops with German-like VOT patterns. Unlike younger Spanish-speaking bilingual children, Spanishspeaking bilingual children at 5 to 6 years of age in the current study demonstrated stop production with voicing lead VOT and all Spanish voiced stops were produced with voicing lead 
VOT at 10 years of age. However, not all Spanish-English bilingual children in the current study produced Spanish stops with lead voicing. Ten out of 17 (59\%) 5- to 6-year-old Spanish-English bilingual children produced lead voicing whereas 11 out of 15 (73\%) 10-year-old bilingual children produced lead voicing for at least one of the stops. Since little information is available on VOT values in monolingual Spanishspeaking children at various ages, it is not certain whether bilingual children in this study showed similar or different characteristics to monolingual Spanish-speaking children. Further studies are warranted to compare Spanish VOT with monolingual Spanish children.

In conclusion, the current study found that SEB children established partially distinctive phonetic categories between languages at age 5 to 6 but fully distinctive phonetic categories by age 10. Further investigations into the VOT patterns of SEB children found cross-language influences between English and Spanish phonetic systems. The current study examined only Spanish and English stops produced by Spanish-English bilingual children without comparison to monolingual English or Spanish children. Further research is warranted to examine whether stops produced by Spanish-English bilingual children are similar or different from these monolingual children in order to fully understand stop production of SpanishEnglish bilingual children.

\section{ACKNOWLEDGMENTS}

This article is based on a master's thesis completed at Texas Tech Univiersity Health Sciences Center in 2015 by the first author under the direction of the second author. The authors express their appreciation to the children and parents who participated in this research.

\section{REFERENCES}

1. U.S. Bureau of the Census. Statistical abstract of the United States. Washington, DC: U.S. Department of Commerce; 2010.

2. Padilla A, Lindholm K. Child bilingualism: The same old issues revisited. In: Martinez J, Mendoza R, editors. Chicano Psychology. Orlando: Academic Press; 1984. p. 369-408.

3. Genesee F, Paradis J, Crago M. Dual language development and disorders: A handbook on bilingualism and second language learning. Baltimore: Paul H. Brookes Pub; 2004.
4. McLaughlin B. Second-language acquisition in childhood. Mahwah, NJ: Lawrence Earlbaum Associates; 1978.

5. Lee S A S, Iverson G. The emergence of phonetic categories in Korean-English bilingual children. J Child Lang. In press. doi:10.1017/ S0305000916000659.

6. Volterra V, Taeschner T. The acquisition and development of language by bilingual children. J Child Lang. 1978;5(02):311-326.

7. Genesse F. Early bilingual development: One language or two? J Child Lang. 1989;16:161-179.

8. Lisker L, Abramson A. A cross-language study of voicing in initial stops: Acoustical measurements. Word. 1964;20:384-422.

9. Macken M, Barton D. The acquisition of the voicing contrast in English: A study of voice onset time in word-initial stop consonants. J Child Lang. 1979;7(1):41-74.

10. Macken M, Barton D. The acquisition of voicing contrast in Spanish: A phonological study of word-initial stop consonants. J Child Lang. 1980;7:433-458.

11. Kehoe M, Lleo C, Rakow M. Voice onset time in bilingual GermanSpanish children. Bilingualism. 2004;7(1):71-88.

12. Deuchar M, Clark A. Early bilingual acquisition of the voicing contrast in English and Spanish. J Phonetics. 1996; 24(3):351-365.

13. Fabiano-Smith L, Bunta F. Voice onset time of voiceless bilabial and velar stops in 3-year-old bilingual children and their agematched monolingual peers. Clin Linguist Phonet. 2012;26(2): 148-163.

14. Khattab G. VOT production in English and Arabic bilingual and monolingual children. Leeds Working Papers in Linguistics and Phonetics. 2000;8:95-122.

15. Lee S A S, Iverson G. Stop consonant productions of Korean-English bilingual children. Biling Lang Cogn. 2012;15(2):275-287.

16. Goldman R, Fristoe M. GFTA-2: Goldman Fristoe 2 Test of Articulation (Second). Circle Pines: American Guidance Service, Inc.; 2000.

17. Fabiano-Smith L, Goldstein B. Phonological acquisition in bilingual Spanish-English speaking children. J of Speech-Lang-Hearing Research. 2010;53:160-178.

18. Gildersleeve-Neumann C, Kester E, Davis B, Pena E. English speech sound development in preschool-aged children from bilingual English-Spanish environments. Lang Speech Hear Ser. 2008;39(3):314-318.

19. Paradis J, Genesee F. Syntactic acquisition in bilingual children: Autonomous or interdependent? Stud Second Lang Acquis. 1996; 18:1-25.

20. Flege J. The phonological basis of a foreign accent: A hypothesis. TESOL Quart. 1981;15(4):443-455.

21. Port R, Mitleb F. Segmental features and implementation in acquisition of English by Arabic speakers. J Phonetics. 1983,11(3):219229.

22. Flege J. Second-language speech training: Theory, findings and problems. In: Winifred Strange, editor. Speech perception and linguistic experience: Issues in cross-language research. Timonium: York Press; 1995. p. 233-272. 